\title{
Effect of prenatal depression during late pregnancy on maternal
}

\section{and neonatal outcomes}

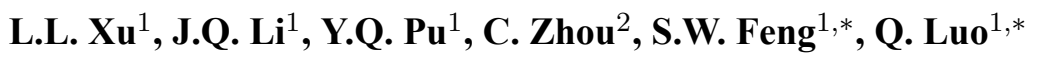 \\ ${ }^{1}$ Department of Obstetrics, Women's Hospital, School of Medicine, Zhejiang University, Zhejiang (P.R. China) \\ ${ }^{2}$ Medical School, Hangzhou Normal University, Zhejiang (P.R. China)
}

\begin{abstract}
Summary
Aim: To determine whether prenatal depression during late pregnancy affect maternal and neonatal outcomes. Methods: The clinical data of 595 pregnant patients in our hospital during January 2016 to December 2017 were studied. These participants were assigned into three groups as mild-to-moderate depression group, severe depression group and non-depression group according to the Edinburgh postnatal depressive scale (EPDS). Results: Compared with the women without depression or with mild-to-moderate depression, pregnant patients with severe depression were likely to suffer from preterm birth $(p<0.05)$. There was no association between the mild-tomoderate depression, severe depression group and the non-depression group about neonatal outcomes (all $p>0.05$ ). Conclusion: Severe prenatal depression during late pregnancy is significantly associated with increased risk of preterm birth, while mild-to-moderate prenatal depression would not affect maternal and neonatal outcomes.
\end{abstract}

Key words: Prenatal depression; Late pregnancy; Preterm birth.

\section{Summary Statement}

What is already known about this topic?

- An increasing number of pregnant patients exhibit symptoms of depression during the childbearing years. The current incidence of prenatal depression is much higher than that of postpartum depression.

- Previous studies have demonstrated that prenatal depression might be associated with adverse maternal and neonatal outcomes.

What this paper adds?

- Severe prenatal depression during late pregnancy is significantly associated with an increased risk of preterm birth, while mild-to-moderate prenatal depression would not affect maternal and neonatal outcomes.

The implications of this paper:

- Depression screening should be used as a routine prenatal screening program.

- Severe depression status during late pregnancy should be regarded as an important indicator for patients at risk for preterm birth.

\section{Introduction}

Depression is the leading cause of the global burden of mental health-related illnesses [1]. Women are at increased risk for depression as compared with men [2]. Pregnancy and postpartum are considered high risk periods [3]. A previous study showed that approximately $12 \%$ of pregnant patients were affected by prenatal depression with depression in the second and third trimester accounting for $12.8 \%$ and $12 \%$ of patients respectively [4].

On the basis of World Health Organizations [5], during the gestation or the postpartum period, $33.3 \%, 10 \%$ of pregnant women in developing and developed countries respectively, suffered from severe mental disorders.

The incidence of the postpartum depression is $17 \%$, while the incidence of the prenatal depression is high as $20 \%$ to $40 \%$ [6]. Prenatal depression is similar to postpartum depression which should be diagnosed early with treatment initiated. However, prenatal depression is often not considered as a vital health issue [7]. The American College of Obstetricians and Gynecologists recommends that clinicians should screen for prenatal depression with a standard tool at least once during pregnancy [8]. Even if the pregnant patient was diagnosed with depression, treatment is often refused secondary to the concern about how the treatment will affect the infant's health [9]. Although there are several studies on prenatal depression [10-12], the research results of the depression on the pregnancy outcomes were inconsistent. Some studies showed that prenatal depression was associated with and preterm birth, low birth weight and intrauterine growth restriction Several reports found no association between prenatal depression and adverse pregnancy outcomes, such as preterm birth, low birth weight and low Apgar scores [13-15].

Therefore, it becomes meaningful to understand the correlation of prenatal depression and with maternal-neonatal outcomes. The aim of this study is to test the hypothesis that prenatal depression during late pregnancy can lead to adverse effects on maternal and neonatal outcomes. In the present the effect of prenatal depression during late pregnancy on maternal and neonatal outcomes in Chinese Han population is investigated. 
Table 1. - Demographic characteristics between the depression group and non-depression group.

\begin{tabular}{|c|c|c|c|c|c|}
\hline Characteristics & Total $(\mathrm{N}=595)$ & Non-depression group $(\mathrm{N}=429)$ & Depression group $(\mathrm{N}=166)$ & $p$-value & $95 \% \mathrm{CI}$ \\
\hline Age (years old) & & & & $0.581^{a}$ & $0.772,1.588$ \\
\hline$<30(\%)$ & 342 & $249(72.8)$ & $93(27.2)$ & & \\
\hline$\geq 30(\%)$ & 253 & $180(71.1)$ & $73(28.9)$ & & \\
\hline Domicile place & & & & $0.037^{a}$ & $1.036,2.391$ \\
\hline Zhejiang province $(\%)$ & 468 & $347(74.1)$ & $121(25.9)$ & & \\
\hline Non-Zhejiang province (\%) & 127 & $82(64.6)$ & $45(35.4)$ & & \\
\hline Residence & & & & $0.001^{b}$ & $0.000,0.001$ \\
\hline City $(\%)$ & 244 & $196(80.3)$ & $48(19.7)$ & & \\
\hline Town $(\%)$ & 216 & $147(68.1)$ & $69(31.9)$ & & \\
\hline Village (\%) & 135 & $86(63.7)$ & $49(36.3)$ & & \\
\hline Education background & & & & $0.452^{b}$ & $0.446,0.465$ \\
\hline Below the high school (\%) & 273 & $193(70.7)$ & $80(29.3)$ & & \\
\hline Junior college (\%) & 93 & $63(67.7)$ & $30(32.3)$ & & \\
\hline Undergraduate (\%) & 180 & $136(75.6)$ & $44(24.4)$ & & \\
\hline Master or above (\%) & 49 & $37(75.5)$ & $12(24.5)$ & & \\
\hline Occupation & & & & $0.126^{a}$ & $0.110,0.122$ \\
\hline Civil servant (\%) & 15 & $7(46.7)$ & $8(53.3)$ & & \\
\hline Teacher $(\%)$ & 73 & $51(69.9)$ & $22(30.1)$ & & \\
\hline Doctor and nurse (\%) & 31 & $18(58.1)$ & $13(41.9)$ & & \\
\hline Worker (\%) & 5 & $5(100.0)$ & $0(0.0)$ & & \\
\hline Company employee (\%) & 336 & $246(72.2)$ & $90(26.8)$ & & \\
\hline Housewife (\%) & 47 & $35(74.5)$ & $12(25.5)$ & & \\
\hline Self-employed (\%) & 53 & $39(73.6)$ & $14(26.4)$ & & \\
\hline Other $(\%)$ & 35 & $28(80.0)$ & $7(20.0)$ & & \\
\hline Personal character & & & & $0.028^{a}$ & $0.032,0.039$ \\
\hline Introvert $(\%)$ & 212 & $141(66.5)$ & $71(33.5)$ & & \\
\hline Extrovert $(\%)$ & 383 & $288(75.2)$ & $95(24.8)$ & & \\
\hline Planned pregnancy & & & & $0.042^{a}$ & $0.044,0.052$ \\
\hline Yes $(\%)$ & 464 & $344(74.1)$ & $120(25.9)$ & & \\
\hline No $(\%)$ & 131 & $85(64.9)$ & $46(35.1)$ & & \\
\hline Adverse pregnancy history & & & & $0.015^{a}$ & $0.014,0.018$ \\
\hline Yes $(\%)$ & 200 & $132(66.0)$ & $68(34.0)$ & & \\
\hline No $(\%)$ & 395 & $297(75.2)$ & $98(24.8)$ & & \\
\hline Monthly household income (yuan) & & & & $0.416^{b}$ & $0.414,0.434$ \\
\hline Below 3000 yuan (\%) & 140 & $96(68.6)$ & $44(31.4)$ & & \\
\hline $3001-4500$ yuan $(\%)$ & 163 & $115(70.6)$ & $48(29.4)$ & & \\
\hline Above 4500 yuan $(\%)$ & 292 & $218(74.7)$ & $74(25.3)$ & & \\
\hline Family condition & & & & $0.048^{b}$ & $0.033,0.040$ \\
\hline Fair $(\%)$ & 154 & $121(78.6)$ & $33(21.4)$ & & \\
\hline General (\%) & 433 & $304(70.2)$ & $129(29.8)$ & & \\
\hline Poor $(\%)$ & 8 & $4(50.0)$ & $4(50.0)$ & & \\
\hline Overall (\%) & 595 & $429(72.1)$ & $166(27.9)$ & & \\
\hline
\end{tabular}

a, Chi-square test; b, Kruskal-Wallis test.

\section{Methods}

Study design and participants

This study set up was illustrated in Figure 1. 630 pregnant women were recruited during their late second and third trimester of pregnancy (24-28 weeks) while attending routine prenatal examinations in the Department of obstetrics of Women's Hospital School of Medicine, Zhejiang University, between January 2016 and December 2017.
The inclusion criteria were Chinese Han population, singleton gestation, age at least 18 years and without medical complications or mental disorders. Fifteen were excluded because they did not meet the inclusion criteria, 8 refused to participate and 12 had to be excluded because they labored in other hospitals. The remaining 595 participants were assigned into three groups and grouping criteria were shown below. After the participants had signed the informed consent form, they would receive two questionnaires including 
Table 2. - Maternal outcomes between the non-depression group and the depression group.

\begin{tabular}{|c|c|c|c|c|c|}
\hline \multirow{2}{*}{ Variable } & \multirow{2}{*}{$\begin{array}{l}\text { Non-depression } \\
\text { group }(\mathrm{N}=429)\end{array}$} & \multicolumn{2}{|c|}{ Depression group $(\mathrm{N}=166)$} & \multirow{2}{*}{$p$-value } & \multirow{2}{*}{$95 \% \mathrm{CI}$} \\
\hline & & $\begin{array}{l}\text { Mild-to-moderate depression } \\
\text { group }(\mathrm{N}=142)\end{array}$ & $\begin{array}{l}\text { Severe depression } \\
\text { group }(\mathrm{N}=24)\end{array}$ & & \\
\hline Labor induction mode & & & & $0.788^{a}$ & $0.791,0.807$ \\
\hline Labor onset (\%) & $303(70.6)$ & $101(71.1)$ & $18(75.0)$ & & \\
\hline Cervical balloon (\%) & $18(4.2)$ & $6(4.2)$ & $2(8.3)$ & & \\
\hline Propess pessary (\%) & $26(6.1)$ & $6(4.2)$ & $0(0.0)$ & & \\
\hline Oxytocin $(\%)$ & $82(19.2)$ & $29(20.4)$ & $4(16.7)$ & & \\
\hline Delivery mode & & & & $0.957^{a}$ & $0.954,0.962$ \\
\hline Natural childbirth $(\%)$ & $308(71.8)$ & $102(71.8)$ & $16(66.7)$ & & \\
\hline Forceps-assisted vaginal birth (\%) & $25(5.8)$ & $8(5.6)$ & $1(4.2)$ & & \\
\hline Cesarean section $(\%)$ & $96(22.4)$ & $32(22.5)$ & $7(29.2)$ & & \\
\hline Use of uteronic agents & & & & $0.622^{a}$ & $0.623,0.642$ \\
\hline Pitocin only $(\%)$ & $39(9.1)$ & $8(5.6)$ & $1(4.2)$ & & \\
\hline Pitocin plus other drugs (\%) & $114(26.6)$ & $43(30.3)$ & $7(29.2)$ & & \\
\hline No use $(\%)$ & $276(64.3)$ & $91(64.1)$ & $16(66.7)$ & & \\
\hline $\begin{array}{l}\text { Intrapartum hemorrhage or } \\
\text { intraoperative hemorrhage }(X \pm S D)\end{array}$ & $261.96 \pm 146.93$ & $262.54 \pm 132.19$ & $258.33 \pm 132.42$ & $0.991^{b}$ & \\
\hline Preterm birth & & & & $0.010^{a}$ & $0.018,0.023$ \\
\hline Yes $(\%)$ & $12(2.8)$ & $2(1.4)$ & $3(12.5)$ & & \\
\hline No $(\%)$ & 417 (97.2) & $140(98.6)$ & $21(87.5)$ & & \\
\hline
\end{tabular}

a, Chi-square test; b, One-way ANOVA; X, mean; SD, standard deviation.

Table 3. - Neonatal outcomes between the non-depression group and the depression group.

\begin{tabular}{|c|c|c|c|c|c|}
\hline \multirow{2}{*}{ Variable } & \multirow[t]{2}{*}{ Non-depression group $(\mathrm{N}=429)$} & \multicolumn{2}{|c|}{ Depression group $(\mathrm{N}=166)$} & \multirow{2}{*}{$p$-value } & \multirow{2}{*}{$95 \% \mathrm{CI}$} \\
\hline & & $\begin{array}{l}\text { Mild-to-moderate depression } \\
\text { group }(\mathrm{N}=142)\end{array}$ & $\begin{array}{l}\text { Severe depression } \\
\text { group }(\mathrm{N}=24)\end{array}$ & & \\
\hline \multicolumn{6}{|l|}{ Apgar scores } \\
\hline $1 \mathrm{~min}$ & $9.87 \pm 0.61$ & $9.89 \pm 0.57$ & $9.96 \pm 0.20$ & $0.748^{b}$ & \\
\hline 5 mins & $9.98 \pm 0.14$ & $9.95 \pm 0.28$ & $10.00 \pm 0.01$ & $0.142^{b}$ & \\
\hline Neonatal birth Weight (g) & $3333.87 \pm 391.63$ & $3320.18 \pm 434.91$ & $3137.50 \pm 508.26$ & $0.072^{b}$ & \\
\hline NICU admission & & & & $0.917^{a}$ & $0.939,0.948$ \\
\hline Yes $(\%)$ & $49(11.4)$ & $18(12.7)$ & $3(12.5)$ & & \\
\hline No $(\%)$ & $380(88.6)$ & $124(87.3)$ & $21(87.5)$ & & \\
\hline Neonatal jaundice & & & & $0.545^{a}$ & $0.556,0.576$ \\
\hline Yes $(\%)$ & $88(20.5)$ & $35(24.6)$ & $6(25.0)$ & & \\
\hline No $(\%)$ & $341(79.5)$ & $107(75.4)$ & $18(75.0)$ & & \\
\hline
\end{tabular}

a, Chi-square test; b, One-way ANOVA; CI, confidence interval.

social demography and the Chinese versions of the Edinburgh Postnatal Depression Scale (EPDS). Four obstetrical nurses were the professional interviewers who received a 2-month psychological training program prior to the start of the study. The interviewees were taken to the specific consulting room to finish the questionnaires with one obstetrical nurse present in order to keep the data as valid as possible.

Data of maternal and neonatal outcomes were gained from the Department of Obstetrics of Women's Hospital School of Medicine, Zhejiang University. All procedures performed in our study involving human participants were in accordance with the ethics committee of the hospital. All participants who volunteered for the complete study were free to pullback from the study at any time. We obtained informed consent of each participant and kept their data confidential.

\section{Measurement instrument}

Demographic characteristics examined include maternal age, place of household registration, residence, education background, occupation, personal character, monthly household income and family condition. Moreover, pregnancy intention (planned or unplanned pregnancy) and adverse pregnancy history were assessed by questionnaire during their prenatal examinations.

Depression was measured using Edinburgh postnatal depressive scale (EPDS). The EPDS is a self-assessment scale including ten items, scored from 0 to 3 ( 0 represented nor- 


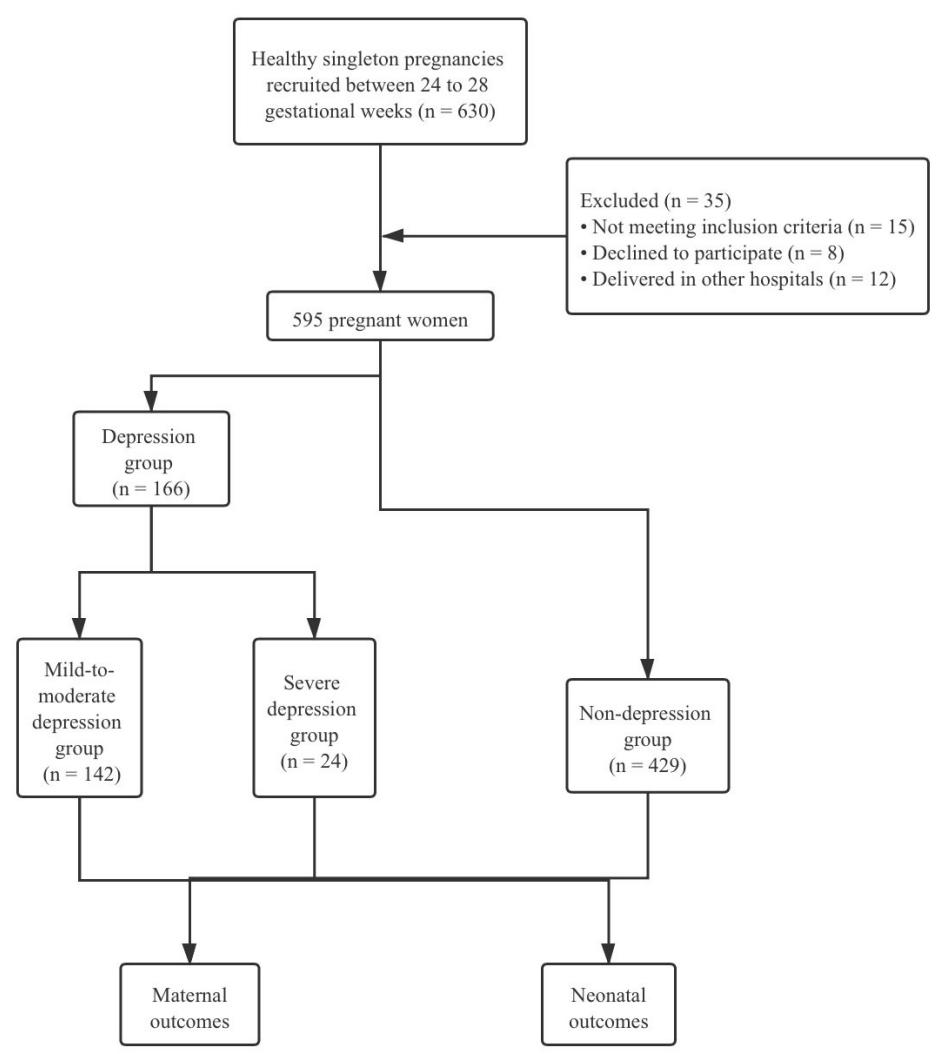

Figure 1. - The procedure of the present study. 630 pregnant women were recruited, 15 were excluded because they did not meet the inclusion criteria, 8 refused to participate and 12 had to be excluded because they labored in other hospitals. After informed consent, matching subjects received a set of questionnaires. 595 participants were divided into three groups according to EPDS scores. The maternal and neonatal outcomes were compared between mild-to-severe depression group, severe depression group and non-depression group.

mal and 3 represented severe) that has been effectively utilized for determining prenatal and postpartum depression [16]. The range of the total score is from 0 to 30 points, and interviewees whose scores are higher represent negative emotion. The recommended cutoff scores include less than 9 points for non-depression, 9 to 12 points for mildto-moderate depression and more than 12 points for severe depression [17]. EPDS was initially used as a screening tool for the postpartum period [18]. Due to the sensitivity of the scale to assess the variation of depression, the sensitivity and specificity are $91 \%$ and $95 \%$ as a predictor for depression in pregnant patients [19]. Cronbach's $\alpha$ was 0.914 [20].

\section{Data analysis}

Data were analyzed using SPSS statistical software version 20.0 (IBM, NY, USA). All data input SPSS were crosschecked for verification. According to the type of data, baseline characteristics were compared using a Chi-square test and Kruskal-Wallis test which were presented as frequency with percentages. Chi-square test and One-way ANOVA were used to compare the variables of maternal and neonatal outcomes of the different groups. $p$ value $<$ 0.05 was considered to reflect statistical significance.

\section{Results}

Demographic characteristics of depression group and non-depression group

From the Table 1, we can see that the incidence of prenatal depression is $27.9 \%(166 / 595)$. We divided the whole group into two as depression group and non-depression group according to 9 points.

Pregnant patients with domicile place of non-Zhejiang province, living in village, introvert personality and poor family condition were likely to develop depression (all $p<$ 0.05). Meanwhile, depressed women had unplanned pregnancies and adverse pregnancy histories $(p<0.05)$. There were no significant association between depression and education background, occupation and monthly household income.

Maternal-neonatal outcomes of mild-to-moderate depression, severe depression group and non-depression group

Compared with the women without depression or with mild-to-moderate depression, pregnant patients with severe depression were likely to suffer from preterm birth $(p<0.05)$. There was no statistically significant difference between mild-to-moderate depression, severe depression group and non-depression group about other maternal 
outcomes including labor induction mode, delivery mode, use of uterotonic agents and hemorrhage (all $p>0.05$ ).

Neonatal outcomes between the mild-to-moderate depression, severe depression group and the non-depression group

There was no association between the mild-to-moderate depression, severe depression group and the non-depression group about other neonatal outcomes including APGAR scores, neonatal birth weight, NICU admission and neonatal jaundice with depression (all $p>0.05$ ).

\section{Discussion}

The main finding of this study shows that severe prenatal depression is significantly associated with the risk of preterm birth, however, mild-to-moderate prenatal depression in late pregnancy does not appear to affect the maternal and neonatal outcomes. It is not obvious to determine the specific association between prenatal depression and preterm birth. From a biological perspective, chronic stress can lead to the alteration of levels of inflammatory proteins [21], accordingly, these changes might cause early contractions and preterm birth [10]. Fransson et al. investigated prenatal depression and determined that a cutoff score of 12 or higher on the EPDS increased the risk for preterm birth (OR, 1.56 (95\% CI), 1.03-2.35) in a Swedish population [22]. Similarly, the research in Finland showed us that pregnancy outcomes were worse among women with severe depression than without [23]. However, other studies demonstrated no significant association between depression and preterm birth. Andersson et al. could not find any association between maternal depression and adverse neonatal outcomes [24]. In their study, depression was measured during the second trimester of pregnancy with the Primary Care Evaluation of Mental disorders (PRIME-MD) patient's questionnaire. Another study showed that subclinical-elevated depressive symptoms during pregnancy measured with self-rating scales were not significantly associated with preterm birth [13]. Evidence was found that different depression screening tools changed the association strength between prenatal depression and preterm birth [11]. In our study, depression was measured during the second and third trimester of pregnancy (24-28 weeks) and the different time point of depression screening was the factor affecting the association between prenatal depression and preterm birth.

In our study, we referred all of the pregnant patients with depression to the psychologists. As a general suggestion, anti-depressive medication exposure during pregnancy was associated with an increased risk of congenital malformations, preterm birth and fetal growth restriction [25]. A study suggested that it was important to take all the side effects of medications into consideration when pregnant patients took psychoactive drugs [26]. One study demonstrated that anger expression and suppression during pregnancy were vulnerable factors for perinatal mental disorders. Specifically anger expression was a predictive factor of mild prenatal depression [27]. A different report noted that anger suppression was associated with depression [28]. We suggested that the association between depression and anger experience and expression during the perinatal period is an interesting topic for further research.

We did not observe any associations of depression with Apgar scores, NICU (neonatal intensive care unit) admission and neonatal birth weight. The results of our study were consistent with the results of what Grigoriadis reported. Our study shows that depression may not influence the mode of the delivery. Similarly, Wu et al. has demonstrated that there was no association between mood and type of delivery [29].

There are still three limitations to our study. One limitation is that assessment of depression was only evaluated in the second or third trimester of pregnancy. We suggest that clinicians should assess depression at different points of time during the gestational period, because it is important to better understand the role that depression during pregnancy plays in fetal growth and development. The second limitation is that we used EPDS scale as the only screening tool to assess depression. It might be better to include face to face interview or other structured psychiatric interview schedules to diagnose depression. The third limitation is the lack of measurement of any blood levels such as blood cortisol.

In general, our finding indicate that prenatal depression screening could be regarded as a routine during perinatal care in China. It is helpful for obstetricians to identify the pregnant patient with severe depression and prevent mild and moderate depression from progressing to severe depression, which could optimize maternal and neonatal outcomes.

\section{Conclusions}

Our present study suggested that severe prenatal depression during late pregnancy measured with the EPDS increased the risk of preterm birth with no other specific adverse outcomes noted to the mother or the infant. Therefore, severe prenatal depression status during late pregnancy should be regarded as an important indicator for a potential adverse outcome in pregnancy and screening of all prenatal patients should be performed.

\section{Ethics Approval and Consent to Participate}

This study was approved by the Research Ethics Committee of Women's Hospital (IRB-20190020-R), Zhejiang University School of Medicine, Hangzhou, China. All participants were informed of the purpose of this study, and written consent was obtained from each participant prior to sample collection.

\section{Acknowledgments}

The study was funded by the National Natural Science Foundation of China (NO. 81571447). Also, it is a part study of Key Research Project of Zhejiang Province 
(NO. 2018C03010) and Construction of Medical Core Subjects and Innovation Platform in Zhejiang Province Grant (2018RC005). We would like to thank the experts and all participating staff of the hospital for their guidance and assistance. We offer special thanks to all participants for their understanding and cooperation.

\section{Conflict of Interest}

The authors declare no conflict of interest.

Submitted: September 08, 2019

Accepted: May 27, 2020

Published: October 15, 2020

\section{References}

[1] Patel V., Chisholm D., Parikh R., Charlson F.J., Degenhardt L., Dua T., et al.: "Addressing the burden of mental, neurological, and substance use disorders: key messages from Disease Control Priorities, 3rd edition". Lancet, 2016, 387, 1672-1685.

[2] Essau C.A., Lewinsohn P.M., Seeley J.R., Sasagawa S.: "Gender differences in the developmental course of depression". J. Affect. Disord., 2010, 127, 185-190.

[3] Stewart D.E.: "Clinical practice. Depression during pregnancy". $N$. Engl. J. Med., 2011, 365, 1605-1611.

[4] Bennett H.A., Einarson A., Taddio A., Koren G., Einarson T.R.: "Prevalence of depression during pregnancy: systematic review". Obstet. Gynecol., 2004, 103, 698-709.

[5] World Health Organization. Maternal mental health and child health and development in low and middle income countries: report of the meeting, Geneva, Switzerland, 30 January - 1 February, 2008.

[6] Andersson L., Sundstrom-Poromaa I., Wulff M., Astrom M., Bixo M.: "Depression and anxiety during pregnancy and six months postpartum: a follow-up study". Acta. Obstet. Gynecol. Scand., 2006, 85, 937-944.

[7] Akkas Yilmaz E., Gulumser C.: "The risk factors, consequences, treatment, and importance of gestational depression". Turk. J. Obstet. Gynecol., 2015, 12, 102-113.

[8] Practice C.o.O.: "Committee Opinion No. 630: Screening for Perinatal Depression”. Obstet. Gynecol., 2015, 125.

[9] Ram D., Gowdappa B., Ashoka H.G., Eiman N.: "Psychopharmacoteratophobia: excessive fear of malformation associated with prescribing psychotropic drugs during pregnancy: an Indian perspective". Indian. J. Pharmacol., 2015, 47, 484-490.

[10] Alder J., Fink N., Bitzer J., Hosli I., Holzgreve W.: "Depression and anxiety during pregnancy: a risk factor for obstetric, fetal and neonatal outcome? A critical review of the literature". J. Matern. Fetal. Neonatal Med., 2007, 20, 189-209.

[11] Grote N.K., Bridge J.A., Gavin A.R., Melville J.L., Iyengar S., Katon W.J.: "A meta-analysis of depression during pregnancy and the risk of preterm birth, low birth weight, and intrauterine growth restriction". Arch. Gen. Psychiatry, 2010, 67, 1012-1024.

[12] Szegda K., Markenson G., Bertone-Johnson E.R., Chasan-Taber L.: "Depression during pregnancy: a risk factor for adverse neonatal outcomes? A critical review of the literature". J. Matern. Fetal. Neonatal Med., 2014, 27, 960-967.

[13] Gawlik S., Waldeier L., Muller M., Szabo A., Sohn C., Reck C.: "Subclinical depressive symptoms during pregnancy and birth outcome-a pilot study in a healthy German sample". Arch. Womens Ment. Health, 2013, 16, 93-100.

[14] Grigoriadis S., VonderPorten E.H., Mamisashvili L., Tomlinson G., Dennis C.L., Koren G., et al.: "The impact of maternal depression during pregnancy on perinatal outcomes: a systematic review and meta-analysis". J. Clin. Psychiatry, 2013, 74, e321-341.

[15] Pesonen A.K., Lahti M., Kuusinen T., Tuovinen S., Villa P., Hamalainen E., et al.: "Maternal prenatal positive affect, depres- sive and anxiety symptoms and birth outcomes: the PREDO study". PLoS One, 2016, 11, e0150058.

[16] Matthey S., Henshaw C., Elliott S., Barnett B.: "Variability in use of cut-off scores and formats on the Edinburgh Postnatal Depression Scale: implications for clinical and research practice". Arch. Womens Ment. Health, 2006, 9, 309-315.

[17] Bergant A.M., Nguyen T., Heim K., Ulmer H., Dapunt O.: "German language version and validation of the Edinburgh postnatal depression scale". Dtsch. Med. Wochenschr, 1998, 123, 35-40.

[18] Cox J.L., Chapman G., Murray D., Jones P.: "Validation of the edinburgh postnatal depression scale (EPDS) in non-postnatal women". J. Affect. Disord., 1996, 39, 185-189.

[19] Matthey S., Barnett B., Kavanagh D.J., Howie P.: "Validation of the edinburgh postnatal depression scale for men, and comparison of item endorsement with their partners". J. Affect. Disord., 2001, 64, 175-184.

[20] Alvarado R., Jadresic E., Guajardo V., Rojas G.: "First validation of a Spanish-translated version of the Edinburgh postnatal depression scale (EPDS) for use in pregnant women. A Chilean study". Arch. Womens Ment. Health, 2015, 18, 607-612.

[21] Washington (DC): National Academies Press (US). Committee on Understanding Premature Birth and Assuring Healthy Outcomes. Preterm Birth: Causes, Consequences, and Prevention., eds Behrman, R.E. \& Butler, A.S.

[22] Fransson E., Ortenstrand A., Hjelmstedt A.: "Antenatal depressive symptoms and preterm birth: a prospective study of a Swedish national sample". Birth, 2011, 38, 10-16.

[23] Raisanen S., Lehto S.M., Nielsen H.S., Gissler M., Kramer M.R., Heinonen S.: "Risk factors for and perinatal outcomes of major depression during pregnancy: a population-based analysis during 2002-2010 in Finland”. BMJ Open, 2014, 4, e004883.

[24] Andersson L., Sundstrom-Poromaa I., Wulff M., Astrom M., Bixo M.: "Neonatal outcome following maternal antenatal depression and anxiety: a population-based study". Am. J. Epidemiol., 2004, 159, 872-881.

[25] Coughlin C.G., Blackwell K.A., Bartley C., Hay M., Yonkers K.A., Bloch M.H.: "Obstetric and neonatal outcomes after antipsychotic medication exposure in pregnancy". Obstet. Gynecol., 2015, 125, 1224-1235.

[26] Vitale S.G., Lagana A.S., Muscatello M.R., La Rosa V.L., Curro V., Pandolfo G., et al.: "Psychopharmacotherapy in pregnancy and breastfeeding”. Obstet. Gynecol. Surv., 2016, 71, 721-733.

[27] Bruno A., Lagana A.S., Leonardi V., Greco D., Merlino M., Vitale S.G., et al.: "Inside-out: the role of anger experience and expression in the development of postpartum mood disorders". J. Matern. Fetal. Neonatal Med., 2018, 31, 3033-3038.

[28] Aldinger M., Stopsack M., Barnow S., Rambau S., Spitzer C., Schnell K., et al.: "The association between depressive symptoms and emotion recognition is moderated by emotion regulation". Psychiatry Res., 2013, 205, 59-66.

[29] Wu J., Viguera A., Riley L., Cohen L., Ecker J.: "Mood disturbance in pregnancy and the mode of delivery". Am. J. Obstet. Gynecol., 2002, 187, 864-867.

Corresponding Author:

SUWEN FENG, M.D., Ph.D.

Department of Nursing, Women's Hospital, School of Medicine, Zhejiang University, 1 Xueshi Road, Hangzhou, 310006 (P.R. China) e-mail: fengsw@zju.edu.cn

QIONG LUO, M.D., Ph.D.

Department of Obstetrics, Women's Hospital, School of Medicine, Zhejiang University, 1 Xueshi Road, Hangzhou, 310006 (P.R. China) e-mail: luoq@zju.edu.cn 